\title{
ORIGINAL ARTICLE \\ Prevalence of Metabolic Syndrome and Lifestyle Characteristics by Business Type among Japanese Workers in Small- and Medium-sized Enterprises
}

\author{
Hiroko Hozawa, ${ }^{1}$ Ayano Takeuchi ${ }^{3}$ and Yuko Oguma ${ }^{1,2}$ \\ ${ }^{1}$ Sports Medicine Research Center, Keio University, Kanagawa, Japan \\ ${ }^{2}$ Graduate School of Health Management, Keio University, Kanagawa, Japan \\ ${ }^{3}$ Department of Preventive Medicine and Public Health, Keio University, School of Medicine, Tokyo, Japan
}

(Received for publication on June 19, 2018)

(Revised for publication on October 30, 2018)

(Accepted for publication on November 8, 2018)

(Published online in advance on December 14, 2018)

\begin{abstract}
This cross-sectional study investigated the associations of business type with the prevalence of metabolic syndrome (MetS) and lifestyle characteristics among workers in small- and medium-sized enterprises. In total, data from 167,736 workers $(114,746$ men and 52,990 women) who participated in health checkups in 2013 were analyzed using multilevel logistic regression models. The odds ratios (ORs) of having MetS, defined based on the criteria of the joint interim statement, were significantly higher in employees of transportation businesses (reference $\mathrm{OR}=1$ ) than in other business types among men (OR: $0.67-0.85)$ and similar result was observed among women (OR: $0.70-0.88)$. The prevalence of a smoking habit was significantly higher in transportation workers than in employees of other businesses for both men and women. Furthermore, male transportation workers were more likely to skip breakfast, engage in $<1 \mathrm{~h} /$ day of walking, walk at a slower speed, and eat dinner just before going to bed. Female transportation workers were more likely to have gained $10 \mathrm{~kg}$ since the age of 20 years. In conclusion, the prevalence of MetS was higher in transportation workers than in workers from other businesses; the associated risk factors may also vary by sex. To effectively promote public health, the labor environment, such as the business type, should be considered. (DOI: 10.2302/kjm.2018-0007-OA; Keio J Med 68 (3) : 54-67, September 2019)
\end{abstract}

Keywords: occupational health, health risk behaviors, metabolic syndrome, small business, SME

\section{Introduction}

To reduce cardiovascular disease, healthcare professionals have focused on control of low-density lipoprotein cholesterol (LDL-C). However, because cardiovascular disease can still develop even with control of LDL-C, and because it was revealed that multiple risk factors are involved (mainly insulin resistance and abdominal obesity) ${ }^{1}$ metabolic syndrome (MetS) has been identified as a residual risk factor for cardiovascular disease, ${ }^{2}$ which is a major public health issue worldwide. ${ }^{3-5}$
Risk factors for MetS include lifestyle habits, such as alcohol intake, dietary intake, and a lack of regular exercise. ${ }^{6-8}$ Regarding physical activity in Japan, only a minority of men $(20.3 \%)$ and women $(13.4 \%)$ in their 40 s exercise regularly. ${ }^{9}$ In Japan, $25.6 \%$ of men and $14.9 \%$ of women in their 40 s skip breakfast. ${ }^{9}$ Therefore, middleaged workers, in particular, need support to improve their lifestyle habits to prevent MetS and other lifestyle-related diseases.

It is especially difficult to reach workers in small- and medium-sized enterprises (SMEs). This is important,

Reprint requests to: Yuko Oguma, PhD, MD, MPH, Keio University, Sports Medicine Research Center, 4-1-1 Hiyoshi, Kohoku-ku, Yokohama, Kanagawa 223-8521, Japan, E-mail: yoguma@keio.jp

Copyright (C) 2018 by The Keio Journal of Medicine 
because health risks are reportedly significantly more prevalent in employees of SMEs $(<300$ employees) than in those employed by large-scale enterprises $(\geq 1,000$ employees). ${ }^{10,11}$ Furthermore, because of the diversity in working hours, type of employment, and workplaces, addressing health education and habits in the labor environment of these workers is warranted to improve health behavior. Such ecological models are an effective way to promote health behavior. ${ }^{12}$

To approach workers in the SME environment, business type is one factor to be considered. However, considering the labor environment, only a few studies have reported the association between health outcome and business type, ${ }^{10,13,14}$ albeit with inconsistent results. Of these, one study showed that the prevalence of MetS was significantly higher in men employed in construction; ${ }^{14}$ however the company size in that study was not clear.

Therefore, to better understand the relationship between the business type and MetS risk factors in SMEs, this study aimed to analyze the prevalence of MetS and related lifestyle characteristics among workers in SMEs ( $<300$ workers) according to the business type.

\section{Materials and Methods}

\section{Study participants}

According to the Statistics Bureau, Ministry of Internal Affairs and Communications, $99.4 \%$ of all enterprises in Japan are small or medium in size..$^{15}$ In 2013, health checkups for 240,022 workers aged 35-74 years were conducted in a prefecture in Japan by a health insurance association that provides insurance for laborers and SMEs ( $<10$ employees, 39,586 [16.5\%]; 10-29 employees, 48,653 [20.3\%]; 30-49 employees, 23,617 [9.8\%]; 50-99 employees, 35,391 [14.7\%]; 100-299 employees, 37,447 [15.6\%]; 300-999 employees, 25,286 [10.5\%]; $\geq 1,000$ employees, 19,767 [8.2\%]; whose company size is unclear, $10,275[4.4 \%])$. In the current study, we defined SMEs as companies with $<300$ employees, in accordance with previous studies. ${ }^{10,11}$ We determined the number of workers in each enterprise by using the number of workers insured for each company, which was calculated in March 2013.

Workers who participated in health checkups and who worked at companies with 300 employees $(n=45,053)$ or more or whose company size was unclear $(n=10,275)$ were excluded. Workers who participated in health checkups and whose age and sex were unclear $(\mathrm{n}=144)$, whose data regarding MetS diagnostic criteria were unavailable $(n=16,356)$, or who did not have company data $(n=458)$ were also excluded. Thus, the final analytic sample consisted of 167,736 workers (Fig. 1). The participation rate in checkups in 2013 was $43.1 \%$. Dependents of workers were not included in the current study.

During their checkups, the participants answered a self-administered questionnaire that covered their smoking, alcohol consumption, physical activity, dietary, and sleep habits. Trained staff then measured the height, weight, waist circumference, and blood pressure of each participant and collected blood samples.

\section{Measurements}

Body weight $(\mathrm{kg})$ and height $(\mathrm{cm})$ were measured using a digital scale and stadiometer, respectively, with the participant barefoot. The body mass index (BMI) was calculated as body weight $(\mathrm{kg})$ divided by the square of body height $(\mathrm{m})$. The waist circumference was measured at the level of the navel and during the late expiratory phase with the participant in the standing position. Blood pressure was measured twice using an automated sphygmomanometer with the participant in the seated position, and the mean value for each participant was recorded. Triglycerides, high-density lipoprotein cholesterol (HDLC), and fasting glucose levels were measured using the blood samples. The fasting condition was confirmed by inquiry ( $>10 \mathrm{~h}$ without a meal). If the participant could not confirm fasting, the HbAlc level was also measured. MetS was diagnosed based on the presence of three of the following five risk criteria from the joint statement by the International Diabetes Federation; the American Heart Association; National Heart, Lung, and Blood Institute; World Heart Federation; International Atherosclerosis Society; and International Association for the Study of Obesity ${ }^{16}$ : (1) waist circumference $\geq 90 \mathrm{~cm}$ in men and $\geq 80 \mathrm{~cm}$ in women (based on Asian populations); (2) hypertension: systolic blood pressure $\geq 130 \mathrm{mmHg}$, diastolic blood pressure $\geq 85 \mathrm{mmHg}$, or treatment with antihypertensive drugs; (3) high fasting glucose $\geq 100 \mathrm{mg}$ / $\mathrm{dL}$ or treatment with antihyperglycemic drugs (if the participant was not fasting, HbAlc (NGSP) $>5.6 \%$ was used instead ${ }^{17}$ ); (4) hypertriglyceridemia $\geq 150 \mathrm{mg} / \mathrm{dL}$ or treatment with antihypertriglyceridemic drugs; and (5) low HDL-C $<40 \mathrm{mg} / \mathrm{dL}$ in men and $<50 \mathrm{mg} / \mathrm{dL}$ in women or treatment with drugs to raise HDL-C level.

Appendix 1 displays the self-administered questionnaire. We included 12 questions related to lifestyle habits in this study. The following responses were classified as high risk: weight gain, "yes" to "Have you gained $\geq 10 \mathrm{~kg}$ since you were 20 years old?"; dietary habits, "yes" to "Do you have an evening meal within $2 \mathrm{~h}$ before bedtime 3 days or more per week?" "Do you eat after the evening meal (have a fourth meal) 3 days or more per week?" and "Do you skip breakfast 3 days or more per week?"; speed of eating, "faster" to "How fast do you eat compared to others?"; and physical activity and sleeping habits, "no" to "Have you been exercising at least 2 days per week, at least 30 minutes each at an intensity that causes a slight sweat, for at least 1 year?" (no to low-intensity exercise), "Do you walk for at least $1 \mathrm{~h}$ every day or have equivalent 
Workers aged $35-74$ years, who comprise the target group for health checkups $(n=556,895)$

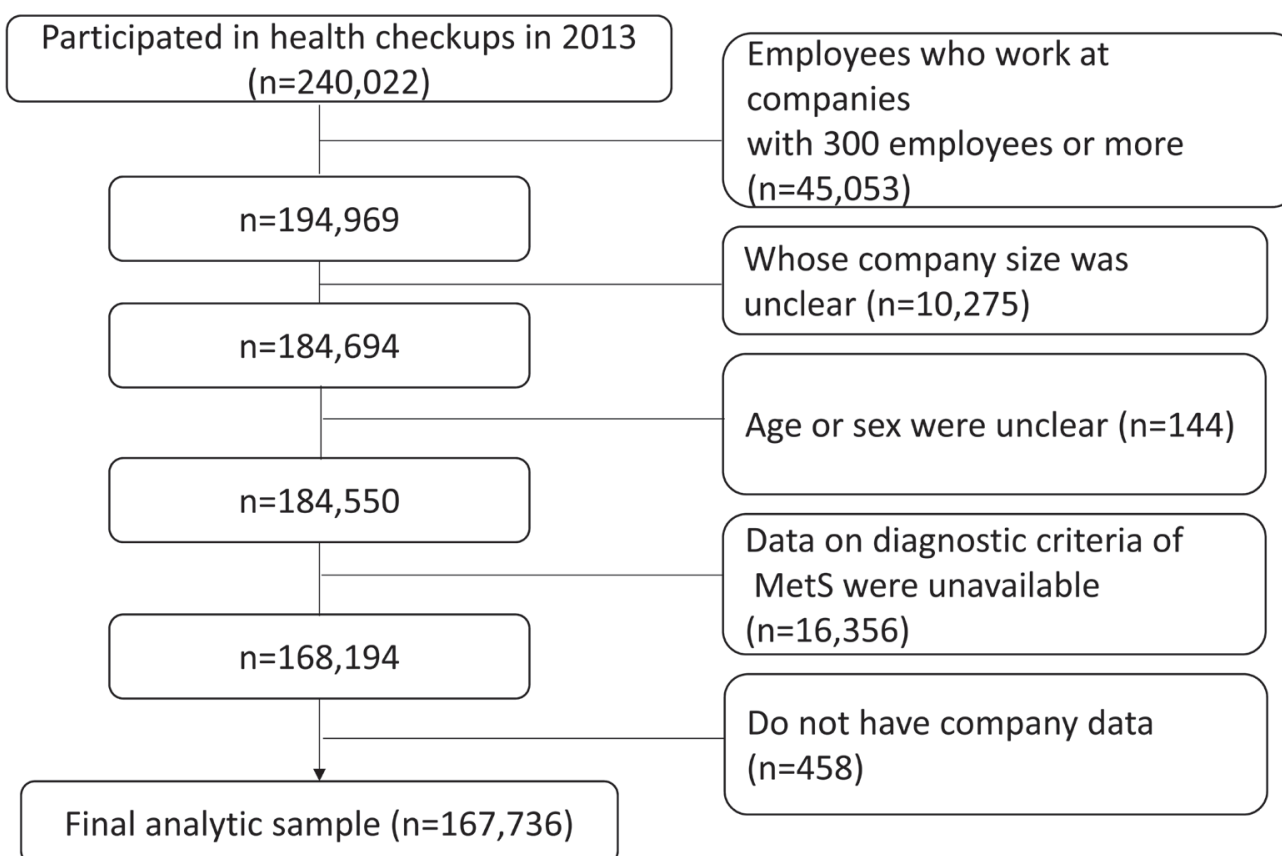

Fig. 1 Flowchart of enrollment.

physical activities in your daily life?" (engage in $<1 \mathrm{~h} /$ day of walking), "Do you walk faster than people of your age and sex?" (walk at a slower speed), and "Do you feel refreshed after a night's sleep?" (not feel refreshed after a night's sleep). For the questions regarding drinking habits, drinking "every day" or "sometimes" and $\geq 1$ serving were classified as high risk (there is a possibility of consuming $>40 \mathrm{~g} /$ day of pure alcohol in men and $>20 \mathrm{~g} /$ day in women). ${ }^{10,18}$

\section{Statistical analysis}

For the analysis, the participants were classified by age group (35-40, 41-50, 51-60, 61-70, and 71-74 years) and by business type. According to the Economic Census for Business Frame, ${ }^{19}$ there are 42 industrial classifications in 18 categories, which are further classified into eight similar business types: (1) transportation, (2) construction, (3) manufacturing, (4) information and communication, (5) wholesale trade, (6) services, (7) healthcare, and (8) others. Company size was classified into five groups $(<10,10-29,30-49,50-99$, and 100-299 employees) by referring to the Economic Census for Business Frame. ${ }^{19}$

The proportion of participants with health risks and differences in company size by business type were assessed using chi-squared tests. Multilevel mixed-effects logistic regression (the GENLINMIXED module: GLMM), which accounts for multilevel measurements per participant and the nesting of participants within companies, was used to examine associations of MetS $(0=$ no MetS, $1=$ presence of MetS) and other participant characteristics (current smoking: $0=$ current non-smoker, $1=$ smoker; other lifestyle characteristics: $0=$ no, $1=$ yes) with business type (with transportation as the reference). The odds ratios (ORs) and 95\% confidence intervals (CIs) were calculated for each factor. The models were adjusted for age and company size. In addition, we confirmed each variable with a $95 \%$ CI by inversing the reference of raw data. To confirm the association between MetS and lifestyle habits, we conducted multilevel logistic regression by adding each lifestyle habit that was significantly related to business type. All analyses were conducted using the Statistical Package for Social Sciences (SPSS) Statistics, version 23 (IBM Japan).

\section{Ethical Issues}

Comprehensive agreement to participate in the study was included in the Medical Consultation Form, in which participants were informed that the data from the health checkups might be used for anonymous statistical analysis. This study was approved by the Ethics Committee of the Graduate School of Health Management, Keio University, Kanagawa, Japan (No. 2015-06). 


\section{Results}

Tables 1 and $\mathbf{2}$ display the participant characteristics and lifestyle habits, respectively. The mean \pm standard deviation (SD) age of the participants was $49.5 \pm 9.9$ years in men and $49.7 \pm 9.1$ years in women; $16.6 \%$ of men and $14.9 \%$ of women had MetS, and $44.9 \%$ of men and $20.3 \%$ of women had a smoking habit. Table 3 displays the company characteristics. Construction made up the largest number of companies (16.2\%), whereas information and communication made up the smallest (3.3\%). The most common company size was $1-9$ employees $(62.2 \%)$, whereas the least common company size was 100-299 employees (2.6\%). Of the different business types, transportation employees showed the highest prevalence of MetS (men, 21.8\%; women, 18.2\%), smoking habit (men, $55.3 \%$; women, $29.4 \%$ ). Transportation also had the highest, or high, values for many other high-risk factors (Table 4).

Because the percentages of participants with MetS were the highest for the transportation business type for both men and women, we conducted multilevel mixed-effects logistic regression using transportation as the reference business type; the results are shown in Fig. 2. The odds ratios (ORs) for having MetS, defined based on criteria of the joint interim statement, were significantly higher in workers of the transportation business (reference OR $=1$ ) than in other business types among men (OR: 0.67-0.85) and similar result was observed among women (OR: $0.70-0.88)$. For both men and women, the prevalence of a smoking habit was significantly higher in transportation workers than in employees of other businesses. Table 5 outlines the lifestyle habits among the different groups of workers. For both men and women, a smoking habit was significantly more prevalent in transportation employees than in employees of other businesses. Furthermore, among men, the ORs for "engage in $<1 \mathrm{~h} /$ day of walking," "walk at a slower speed," "meal before bedtime," and "skipping breakfast" were significantly higher among transportation workers than among employees of other business types. Among women, the OR for "weight gained since age 20 years" was significantly higher in transportation than in other business types. Table 6 shows the results of GLMM by adding each lifestyle habit that was significantly related to business type. All lifestyle habits, except smoking in men and skipping breakfast in women, were significantly related to MetS.

Because participants aged 70-74 years accounted for a very small proportion of the workers, an additional analysis was carried out excluding this group (data not shown). The results were the same except for "meal before bedtime": one business type was not significant for this factor, but similar relations were observed overall.

\section{Discussion}

This cross-sectional study analyzed the associations between business type, the prevalence of MetS, and related lifestyle factors among employees of SMEs. We found that, for both men and women, MetS and related health risk behaviors were significantly more common in transportation workers. This result is consistent with a previous study that found that the prevalences of MetS and hypertension in bus drivers was $49.9 \%$ and $53.3 \%$ which was higher than $23.8 \%$ and $19.7 \%$ in the crafts and machine operators' group, respectively. ${ }^{20}$

The prevalence of MetS in the current study was similar to that in the 2014 Japan Epidemiology Collaboration on Occupational Health (J-ECOH) Study (23.3\% for men and $12.7 \%$ for women). The J-ECOH Study is a large enterprise-based study that included participants aged 20-69 years and which used the same criteria for MetS as our study did. ${ }^{21}$

Furthermore, the current study revealed that male transportation workers were significantly more likely to skip breakfast, engage in $<1 \mathrm{~h}$ /day of walking, walk at a slower speed, and have dinner just before going to bed than those in other business categories. Female transportation workers were significantly more likely to have gained $10 \mathrm{~kg}$ since the age of 20 years. Japanese guidelines recommend $1 \mathrm{~h}$ per day of physical activity at an intensity level of at least 3 metabolic equivalents for 18-64 years, ${ }^{22}$ and gait speed is known to be associated with survival in older adults. ${ }^{23}$ Considering dietary habits and weight gain, both skipping breakfast ${ }^{24,25}$ and weight gain from age 20 years $^{26,27}$ are associated with the development of MetS. Moreover, according to the Survey on Industrial Accidents, transportation workers have the highest number of insurance claims for cerebral and cardiac diseases $(26 \%){ }^{28}$ Consequently, it might be effective to promote improvement in these unhealthy lifestyle habits among transportation workers to prevent MetS; such measures could also help prevent cardiovascular disease.

The prevalence of a smoking habit in the J-ECOH Study was $18 \%$ overall, $30.1 \%$ in men, and $8.0 \%$ in women ${ }^{21}$; the rates in men and women were both higher than national results obtained from people aged more than 30 years. ${ }^{9}$ Moreover, the prevalence of smoking in the current study was higher than that in the J-ECOH Study, especially among transportation workers. Because smoking coupled with obesity contributes substantially to all-cause mortality, ${ }^{29}$ smoking cessation programs targeted toward the transportation industry could be an important population-based approach for the prevention of cardiovascular diseases. The Monthly Labor Survey reported that the average working hours were $149.0 \mathrm{~h} /$ month across all business types, whereas transportation workers worked $170.9 \mathrm{~h} /$ month. This is the second longest working hour duration among the different business types after those of construction workers, who work $174.5 \mathrm{~h} /$ month. ${ }^{30}$ Previ- 
Table 1. Participant characteristics

\begin{tabular}{|c|c|c|}
\hline Variable & $\operatorname{Men}(\mathrm{n}=114,746)$ & Women $(\mathrm{n}=52,990)$ \\
\hline \multicolumn{3}{|l|}{ Individual level } \\
\hline Age (years) ${ }^{* 1}$ & $49.5 \pm 9.9$ & $49.7 \pm 9.1$ \\
\hline \multicolumn{3}{|l|}{ Age group (years) ${ }^{* 2}$} \\
\hline $35-39$ & $19,150(17.7)$ & $7,487(14.9)$ \\
\hline $40-49$ & $41,207(38.2)$ & $18,942(37.6)$ \\
\hline $50-59$ & $25,676(23.8)$ & $15,551(30.9)$ \\
\hline $60-69$ & $19,520(18.1)$ & $7,597(15.1)$ \\
\hline $70-74$ & $2,387(2.2)$ & $795(1.6)$ \\
\hline Body height $(\mathrm{cm}){ }^{* 1}$ & $170.1 \pm 0.1$ & $157.5 \pm 0.1$ \\
\hline Body weight $(\mathrm{kg})^{* 1}$ & $69.5 \pm 11.6$ & $54.9 \pm 9.8$ \\
\hline $\operatorname{BMI}\left(\mathrm{kg} / \mathrm{m}^{2}\right)^{* 1}$ & $24.0 \pm 3.6$ & $22.1 \pm 3.8$ \\
\hline Waist circumference $(\mathrm{cm}){ }^{* 1}$ & $84.6 \pm 9.6$ & $78.4 \pm 10.4$ \\
\hline High level of low-density lipoprotein cholesterol $\mathrm{a}^{* 2}$ & $17,830(15.5)$ & $6,550(12.4)$ \\
\hline Large waist circumference & $29,941(26.1)$ & $20,848(39.3)$ \\
\hline Hypertension & $53,489(46.6)$ & $14,516(27.4)$ \\
\hline Hyperglycemia & $47,284(41.2)$ & $13,213(24.9)$ \\
\hline Hypertriglyceridemia & $38,035(33.1)$ & $7,364(13.9)$ \\
\hline Low high-density lipoprotein cholesterol & $14,709(12.8)$ & $7,469(14.1)$ \\
\hline Metabolic syndrome ${ }^{b * 2}$ & 18,993 (16.6.) & $7,917(14.9)$ \\
\hline Large waist circumference & $12,098(63.7)$ & $6,982(88.2)$ \\
\hline Hypertension & $15,726(82.8)$ & $6,000(75.8)$ \\
\hline Hyperglycemia & $15,613(82.2)$ & $6,514(82.3)$ \\
\hline Hypertriglyceridemia & $15,227(80.2)$ & $5,330(67.3)$ \\
\hline Low high-density lipoprotein cholesterol & $11,129(58.6)$ & $5,069(64.0)$ \\
\hline \multicolumn{3}{|l|}{ Company level } \\
\hline \multicolumn{3}{|l|}{ Business type ${ }^{* 2}$} \\
\hline Construction & $15,266(13.3)$ & $3,247(6.1)$ \\
\hline Manufacturing & $26,201(22.8)$ & $8,170(15.4)$ \\
\hline Information and communication & $2,343(2.0)$ & $616(1.2)$ \\
\hline Transportation & $13,631(11.9)$ & $1,752(3.3)$ \\
\hline Wholesale trade & $16,157(14.1)$ & 7,371 (13.9) \\
\hline Services & $19,462(17.0)$ & $8,822(16.6)$ \\
\hline Healthcare & $6,354(5.5)$ & $14,726(27.8)$ \\
\hline Others & $15,332(13.8)$ & $8,286(15.6)$ \\
\hline \multicolumn{3}{|l|}{ Company size (number of employees) ${ }^{* 2}$} \\
\hline $1-9$ & $24,218(21.1)$ & $11,360(21.4)$ \\
\hline $10-29$ & $30,711(26.8)$ & $13,741(25.9)$ \\
\hline $30-49$ & $14,987(13.1)$ & $6,610(12.5)$ \\
\hline $50-99$ & $21,592(18.8)$ & 10,525 (19.9) \\
\hline $100-299$ & $23,238(20.3)$ & $10,754(20.3)$ \\
\hline
\end{tabular}

${ }^{* 1}$ Mean $\pm \mathrm{SD},{ }^{* 2}$ number $(\%)$.

${ }^{a}$ High low-density lipoprotein cholesterol $\geq 160 \mathrm{mg} / \mathrm{dL}$.

${ }^{b}$ Metabolic syndrome was diagnosed based on the presence of three of the five risk criteria from the joint statement by the International Diabetes Federation; American Heart Association; National Heart, Lung, and Blood Institute; World Heart Federation, International Atherosclerosis Society; and International Association for the Study of Obesity. ${ }^{10}$ 
Table 2. Participant lifestyle habits

\begin{tabular}{lcccc}
\hline \hline Variable & \multicolumn{2}{c}{ Men } & \multicolumn{2}{c}{ Women } \\
\hline Current smoker & $\mathrm{n}$ & $\%$ & $\mathrm{n}$ & $\%$ \\
Gained $\geq 10 \mathrm{~kg}$ since age 20 years & 51,490 & 44.9 & 10,760 & 20.3 \\
Change weight $( \pm 3 \mathrm{~kg}$ in a year) & 34,436 & 45.2 & 9,027 & 24.5 \\
No exercise habit a & 23,065 & 20.1 & 9,694 & 26.4 \\
Engage in $<1$ h/day of walking & 58,046 & 76.3 & 30,427 & 82.7 \\
Walk at a slower speed & 46,339 & 60.8 & 22,649 & 61.6 \\
Eat faster compared to others ${ }^{b}$ & 38,927 & 51.2 & 19,818 & 54.0 \\
Eat dinner before going to bed & 28,353 & 37.4 & 11,265 & 30.9 \\
Eat after the evening meal & 34,052 & 44.7 & 10,651 & 29.0 \\
Skip breakfast & 11,559 & 15.2 & 7,084 & 19.3 \\
Alcohol risk ${ }^{\mathrm{c}}$ & 22,331 & 29.8 & 7,122 & 19.8 \\
Not feel refreshed after a night's sleep & 16,033 & 24.2 & 6,105 & 21.4 \\
\hline
\end{tabular}

a "Have you been exercising at least 2 days per week, at least 30 min each at an intensity that causes a slight sweat, for at least 1 year?"

b The answer "faster" was classified as being associated with higher risk.

${ }^{c}$ Consumption of $>20 \mathrm{~g}$ of alcohol per serving for men ( $\geq 2$ to $<3$ servings) and $>10 \mathrm{~g}$ for women ( $\geq 1$ to $<2$ servings) was classified as high risk. ${ }^{11}$

Table 3. Company characteristics

\begin{tabular}{lcc}
\hline \hline Variable & $(\mathrm{n}=22,567)$ & $\%$ \\
\hline Business type & Number of companies & 16.2 \\
Construction & 3,650 & 14.9 \\
Manufacturing & 3,367 & 3.3 \\
Information and communication & 755 & 4.2 \\
Transportation & 956 & 15.7 \\
Wholesale trade & 3,553 & 14.4 \\
Services & 3,250 & 10.1 \\
Healthcare & 2,290 & 21.0 \\
Others & 4,746 & \\
Company size (number of employees) & & 62.2 \\
$1-9$ & 14,045 & 24.6 \\
$10-29$ & 5,557 & 5.8 \\
$30-49$ & 1,320 & 4.7 \\
$50-99$ & 1,066 & 2.6 \\
$100-299$ & 579 & \\
\hline
\end{tabular}

ous studies have shown that long working hours are associated with poor diet quality, ${ }^{31}$ smoking, ${ }^{32}$ and physical inactivity. ${ }^{33}$ Because transportation workers likely work prolonged hours, it may be difficult for them to maintain healthy lifestyle habits. Among transportation workers, irregular lifestyles can also sometimes cause sleep disorders. ${ }^{34,35}$ Previous studies have shown relationships between sleep apnea syndrome and BMI, ${ }^{36}$ and between sleepiness (Epworth Sleepiness Scale) and BMI and the major components of MetS (waist circumference, hypertension, and hypertriglyceridemia). ${ }^{37}$
Associations of various health-related factors with the business type of transportation have also been reported. $^{38,39}$ One study showed that transportation workers had significantly higher rates of obesity and more frequent smoking habits than the average U.S. worker. ${ }^{39}$

As shown in Table 6, all lifestyle habits except smoking in men and skipping breakfast in women were significantly related to MetS, and a similar association was observed among business types. These findings show that, while lifestyle habits mediate some part of the relationships between business type and MetS, business type 


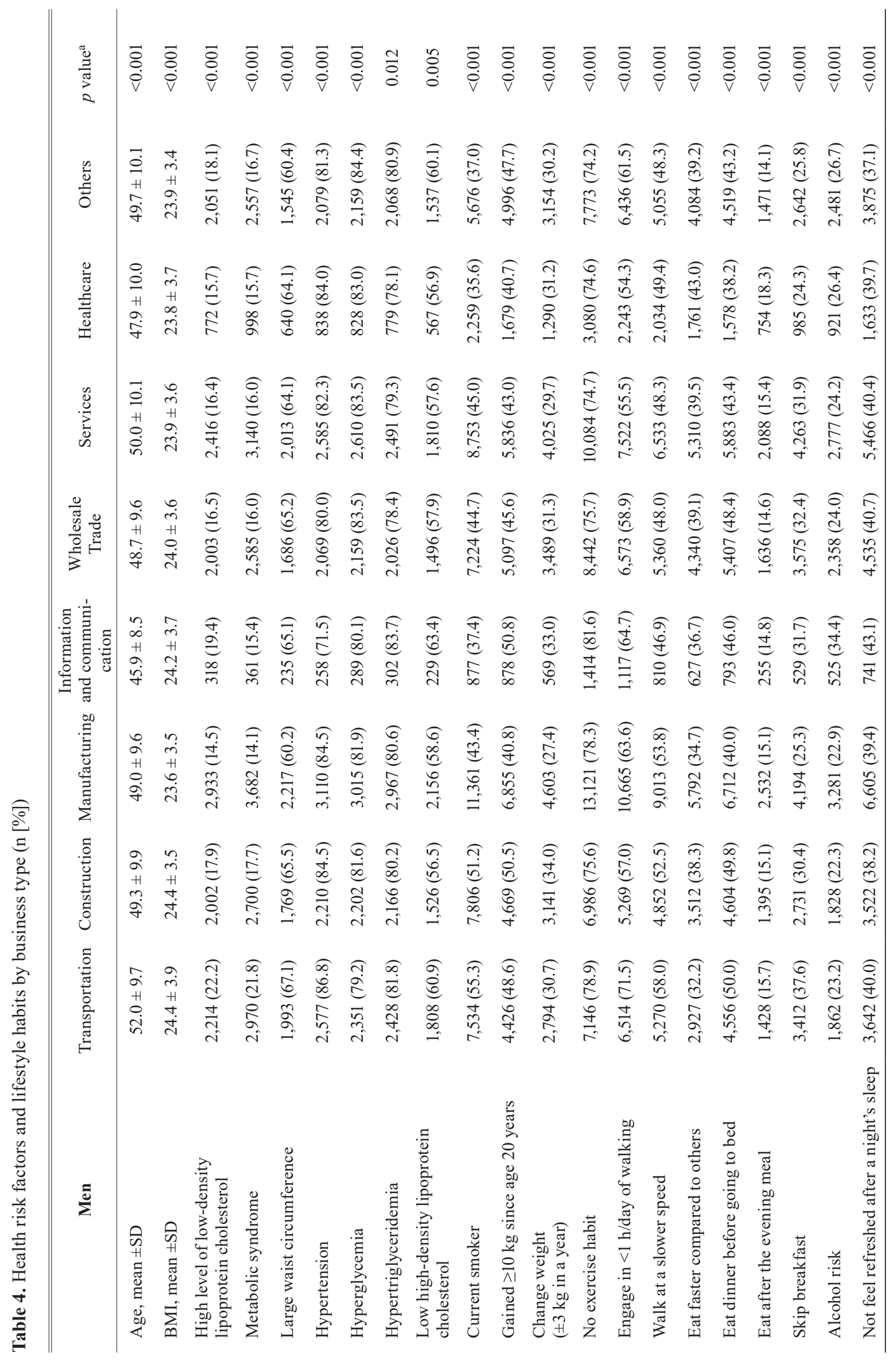




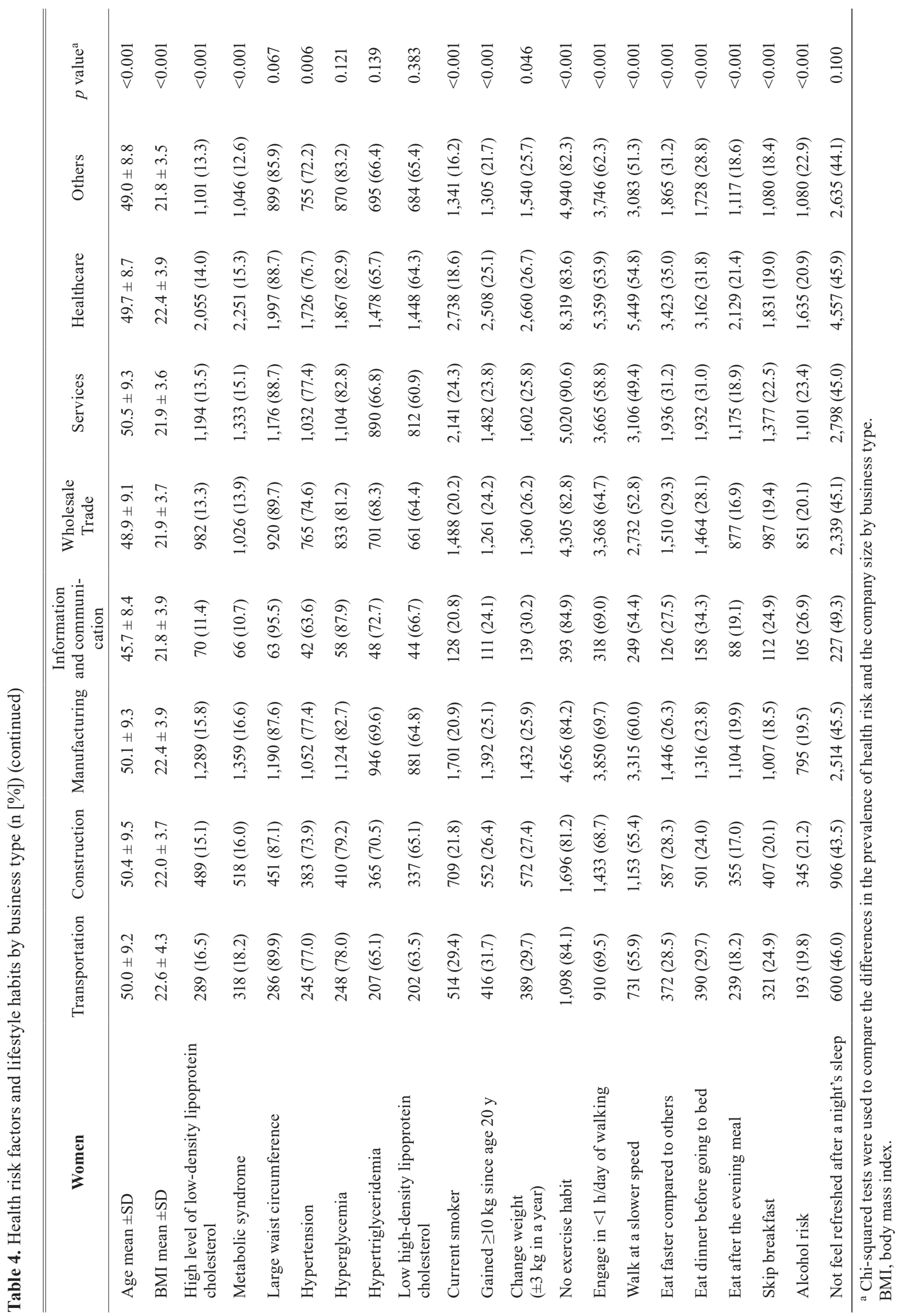




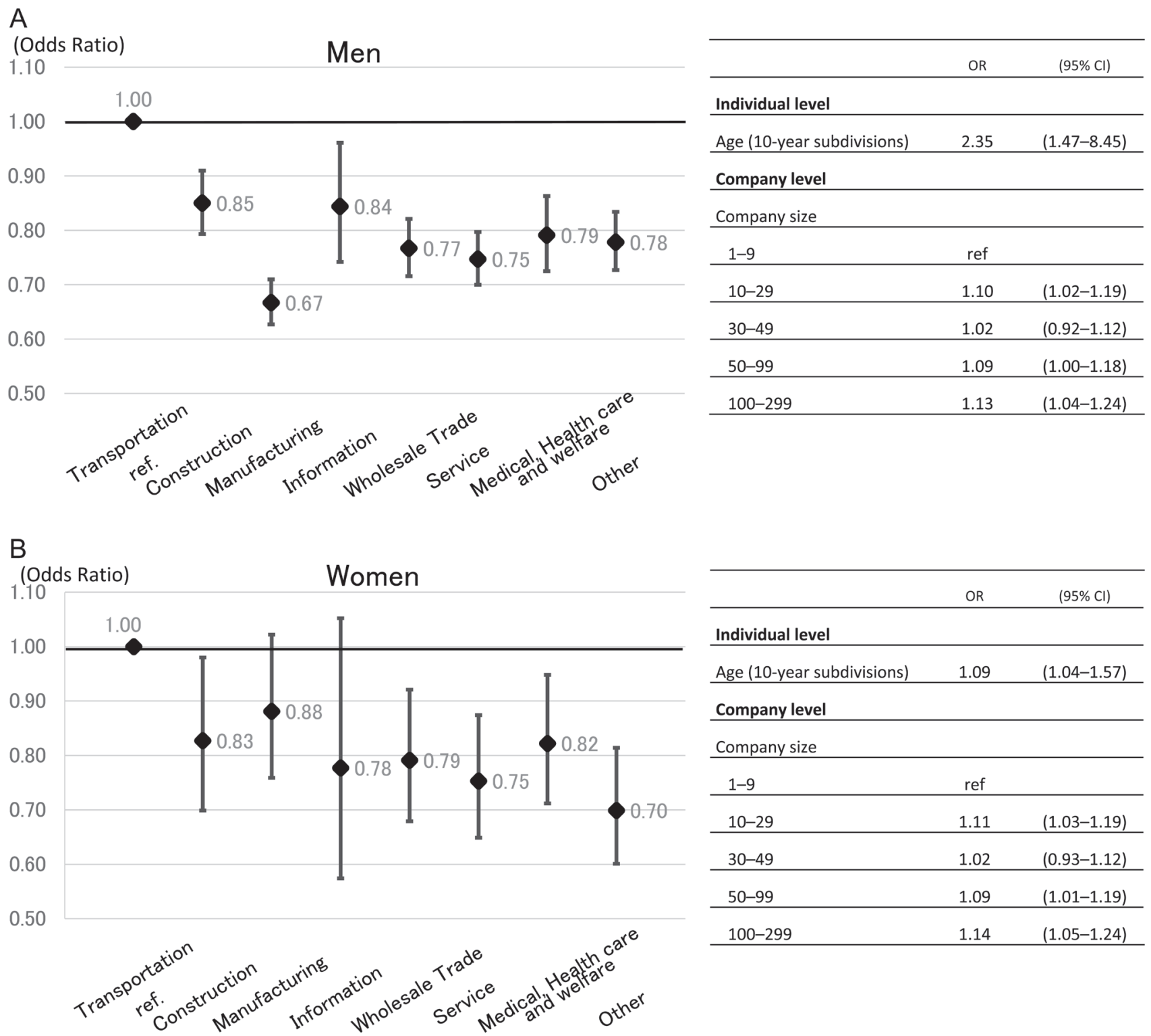

Fig. 2 Results of multilevel analysis showing the odds ratios of having MetS for (A) men and (B) women.

is independently related to MetS. Moreover, we conducted a multilevel logistic regression analysis by adding all lifestyle habits that were significantly related to business type: we added "smoking," "engage in $<1 \mathrm{~h}$ /day of walking," "walk at a slower speed," "meal before bedtime," and "skip breakfast" for men, and "smoking" and "gained $\geq 10 \mathrm{~kg}$ " for women. For men, the lifestyle habits "engage in $<1 \mathrm{~h}$ /day of walking," "walk at a slower speed," and "meal before bedtime" were significantly related to MetS, and a similar association was observed in business type employees in the results of GLMM shown in Table 5. Lifestyle habits were significantly related to MetS in women, but no relationship was observed based on business type. This indicates that business type is more as- sociated with MetS independently in men than in women. Because this study is cross-sectional in nature, additional longitudinal studies are needed to assess the likely causal relationships.

In the current study, we defined MetS based on international criteria. As shown in Table 4, the proportion of those with hypertension, hyperglycemia, and hypertriglyceridemia in almost all business types was greater in men, whereas the proportion of those with a large waist circumference was greater in women. However, the proportion of women with hypertension, and hyperglycemia, although less than that for men, was still very high. To prevent MetS, it might be effective to consider the improvement of the access to drug treatment with support 


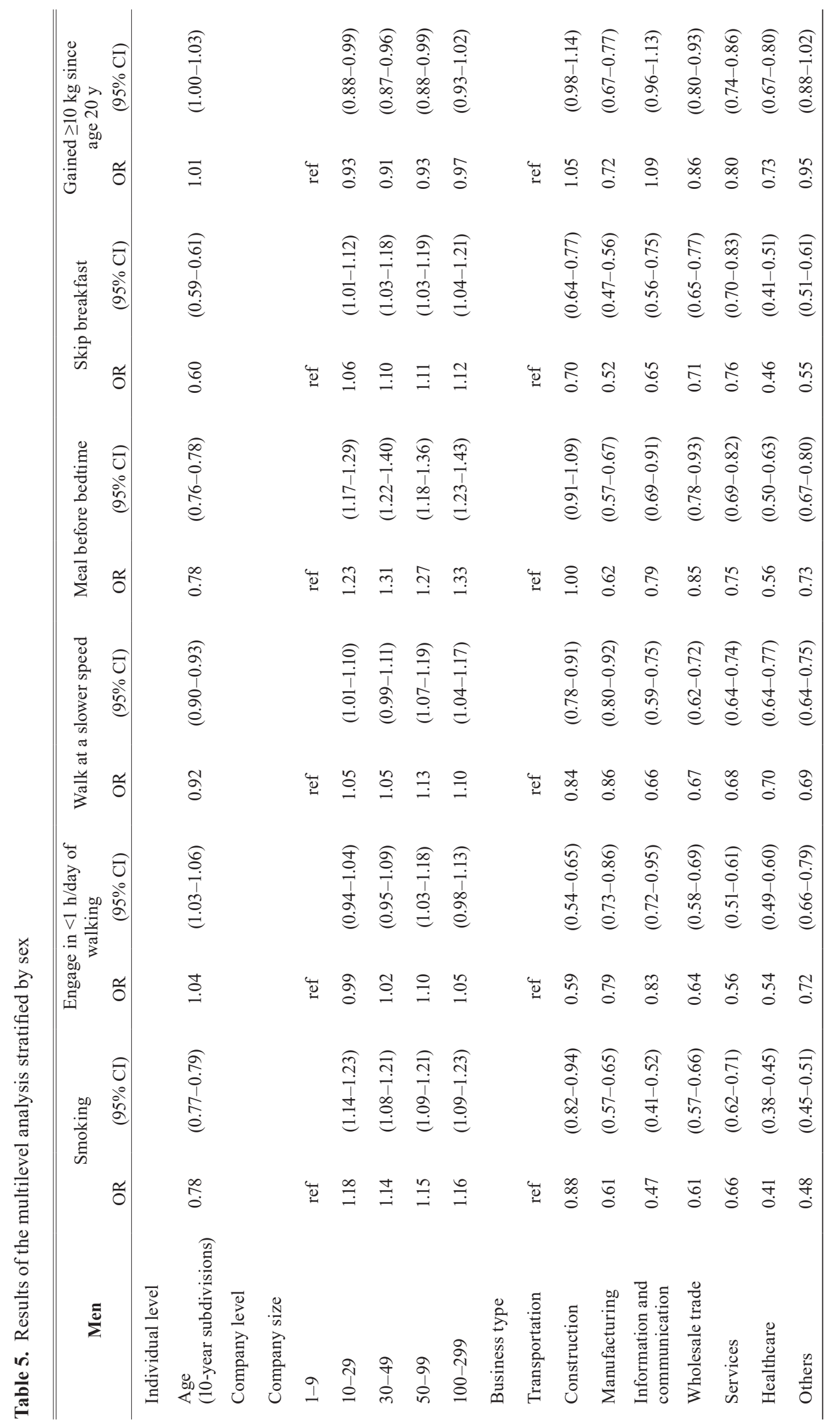




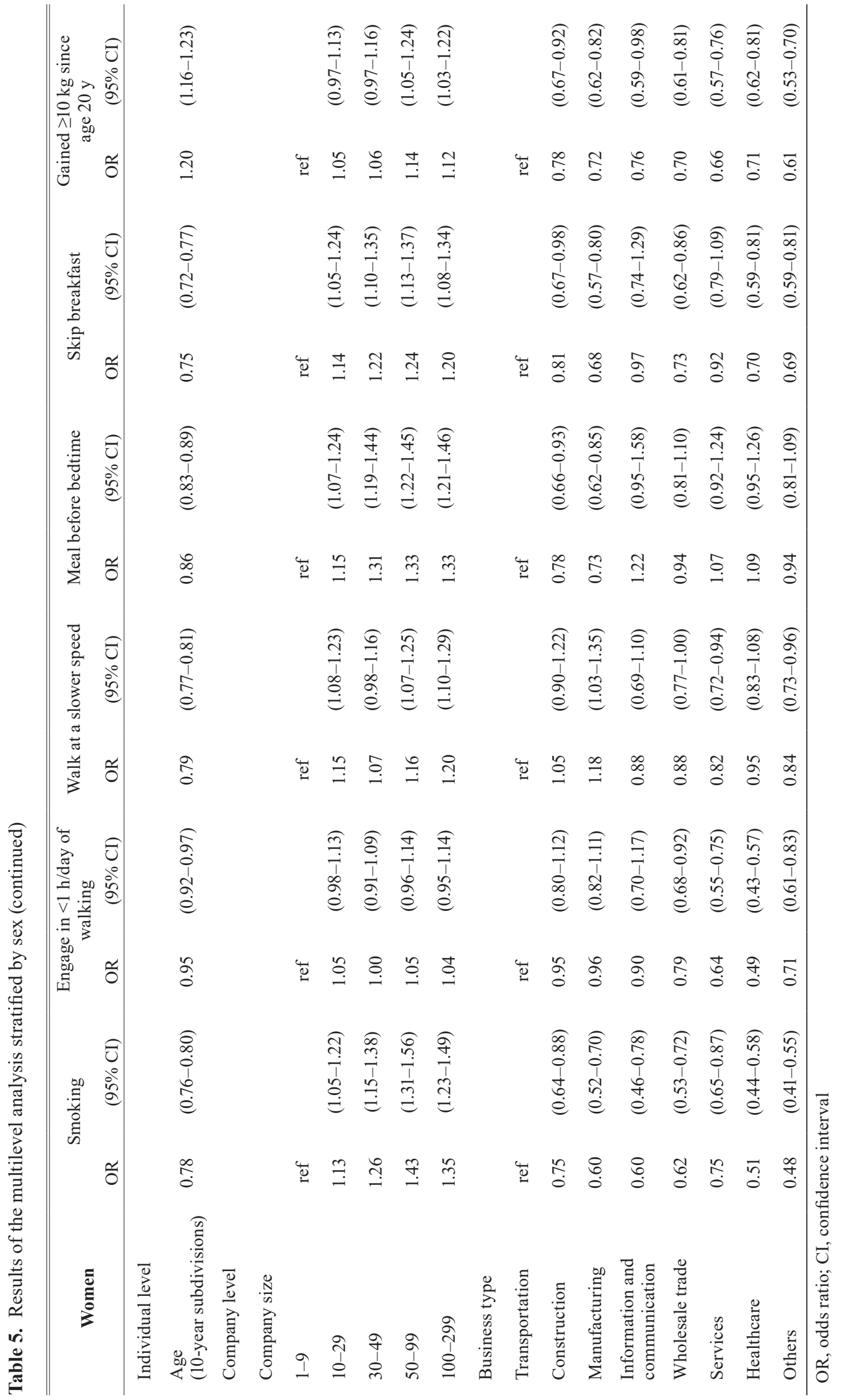




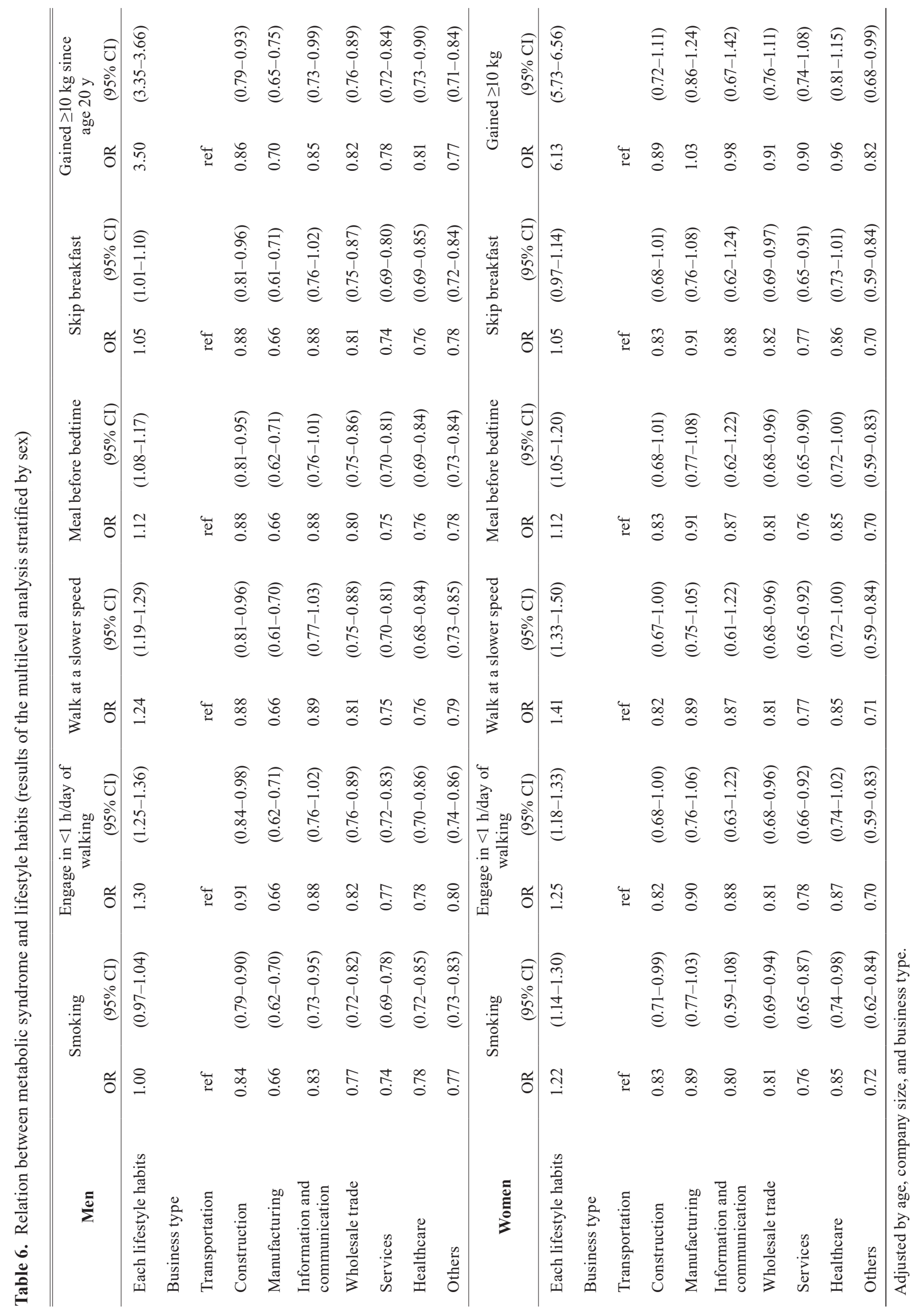


of improving lifestyle habits.

There are several limitations of our study. First, although the business type was clear, the participants' roles in the businesses were unclear. For example, in the transportation industry, there are not only drivers, but also office clerks and sales representatives. Different job types may have differences in sedentary time, the manner of eating, and sleeping time. Because the current findings reveal poor health habits and a high prevalence of MetS among transportation workers, further studies should investigate these findings by job type among workers in the transportation industry. Second, the findings of this study may be confounded by unobserved environmental-level factors, such as family and neighborhood factors, regional factors, and socioeconomic status. Third, there is a possibility of selection bias, because only workers who attended the checkups $(43.1 \%)$ were included. Therefore, it is possible that more health-conscious workers tended to participate in the study, suggesting that the real prevalence of MetS might be higher than that recorded here because of non-participation bias. Fourth, lifestyle habits were evaluated via a self-administered questionnaire. Consequently, these subjective results might be different from the participants' actual lifestyle habits. Despite these limitations, the results of this study are still important: this large-sample study focusing on SMEs suggests that an environmental approach might be useful to prevent MetS in transportation workers. Furthermore, the multilevel analysis showed the effects of business type as an environmental influence in consideration of individual lifestyle habits.

In conclusion, the prevalence of MetS and related unhealthy lifestyle habits were higher in transportation workers than in workers from other business types. The current findings illustrate that the prevalence of MetS and associated lifestyle risk factors vary according to business type and sex. These findings should be considered when developing an environmental approach to improve public health.

\section{Acknowledgments}

This study was funded by the Keio University Doctorate Student Grant-in-Aid Program. We are grateful to the health insurance association and all workers who provided invaluable data.

\section{Conflict of Interest}

The authors declare that there are no conflicts of interest.

\section{References}

1. Campbell CY, Rivera JJ, Blumenthal RS: Residual risk in statintreated patients: future therapeutic options. Curr Cardiol Rep 2007; 9: 499-505. PMID:17999876, DOI:10.1007/BF02938395

2. Okamura T, Kokubo Y, Watanabe M, Higashiyama A, Ono Y, Nishimura K, Okayama A, Miyamoto Y: A revised definition of the metabolic syndrome predicts coronary artery disease and ischemic stroke after adjusting for low density lipoprotein cholesterol in a 13-year cohort study of Japanese: The Suita Study. Atherosclerosis 2011; 217: 201-206. PMID:21481396, DOI:10.1016/j. atherosclerosis.2011.03.010

3. World Health Organization: Fact sheet: cardiovascular diseases (CVDs) 2015. http://www.who.int/mediacentre/factsheets/fs317/ en/. Accessed on July 29, 2017.

4. Lakka HM, Laaksonen DE, Lakka TA, Niskanen LK, Kumpusalo E, Tuomilehto J, Salonen JT: The metabolic syndrome and total and cardiovascular disease mortality in middle-aged men. JAMA 2002; 288: 2709-2716. PMID:12460094, DOI:10.1001/ jama.288.21.2709

5. Bhatnagar A: Environmental determinants of cardiovascular disease. Circ Res 2017; 121: 162-180. PMID:28684622, DOI:10.1161/ CIRCRESAHA.117.306458

6. Zhu S, St-Onge MP, Heshka S, Heymsfield SB: Lifestyle behaviors associated with lower risk of having the metabolic syndrome. Metabolism 2004; 53: 1503-1511. PMID:15536610, DOI:10.1016/j. metabol.2004.04.017

7. Wilsgaard T, Jacobsen BK: Lifestyle factors and incident metabolic syndrome. Diabetes Res Clin Pract 2007; 78: 217-224. PMID:17448561, DOI:10.1016/j.diabres.2007.03.006

8. Mazidi M, Pennathur S, Afshinnia F: Link of dietary patterns with metabolic syndrome: analysis of the National Health and Nutrition Examination Survey. Nutr Diabetes 2017; 7: e255. PMID:28319105, DOI:10.1038/nutd.2017.11

9. Ministry of Health Labour and Welfare National Health and Nutrition Survey 2016. http://www.mhlw.go.jp/stf/houdou/0000142359. html. Accessed on July 29, 2017.

10. Yoshino C, Sugimori H, Tanaka T, Yoshida K: Analysis of secular change of standardized mortality ratios in Japanese companies by size and type of business 1987-1999. St. Marianna Med J 2005; 33: 43-52 (in Japanese).

11. Suzuki H, Honda R, Yamada Y: Health status and habits in workers in small and medium scale enterprises in Ishikawa Prefecture: for the development of effective health promoting services. J Kanazawa Med Univ 2005; 30: 83-90 (in Japanese).

12. Sallis JF, Cervero RB, Ascher W, Henderson KA, Kraft MK, Kerr $\mathrm{J}$ : An ecological approach to creating active living communities. Annu Rev Public Health 2006; 27: 297-322. PMID:16533119, DOI:10.1146/annurev.publhealth.27.021405.102100

13. Oda H, Kido T, Omote S, Naganuma R, Hosomi H: A comparative study of industrial classification of worker's health status based on periodical health examination data in female employees. Kanazawa Univ Repos Acad Resour 2006; 30: 211-223 (in Japanese).

14. Hidaka T, Hayakawa T, Kakamu T, Kumagai T, Hiruta Y, Hata J, Tsuji M, Fukushima T: Prevalence of metabolic syndrome and its components among Japanese workers by clustered business category. PLoS One 2016; 11: e0153368. PMID:27082961, DOI:10.1371/journal.pone. 0153368

15. Economic Census for Business Frame: 2014. http://www.stat. go.jp/data/e-census/2014/kekka.htm. Accessed on July 29, 2017. 
16. Alberti KG, Eckel RH, Grundy SM, Zimmet PZ, Cleeman JI, Donato KA, Fruchart JC, James WP, Loria CM, Smith SC Jr, International Diabetes Federation Task Force on Epidemiology and Prevention; National Heart, Lung, and Blood Institute; American Heart Association; World Heart Federation; International Atherosclerosis Society; and International Association for the Study of Obesity: Harmonizing the metabolic syndrome. Circulation 2009; 120: 1640-1645. PMID:19805654, DOI:10.1161/CIRCULATIONAHA.109.192644

17. Kametani T, Tubono Y, Kosugi H, Satake T, Hasimoto S, Wakamatu S, Yamamoto M, Shibuya N: Prediabetes individuals with HbAlc 5.6-6.4\% and fasting plasma glucose $100-125 \mathrm{mg} / \mathrm{dL}$ at high risk of incident diabetes. Ningen Dock 2017; 32: 544-549.

18. Ministry of Health Labour and Welfare 7th meeting of the way of specified health checkups and specified health guidance 2014 . http://www.mhlw.go.jp/stf/shingi2/0000124501.html. Accessed July 29, 2017.

19. Statistics Bureau: Ministry of Internal Affairs and Communications, Economic Census for Business Frame 2015. http://www. stat.go.jp/data/e-census/2014/index.htm. Accessed on July 29, 2017.

20. Shin SY, Lee CG, Song HS, Kim SH, Lee HS, Jung MS, Yoo SK: Cardiovascular disease risk of bus drivers in a city of Korea. Ann Occup Environ Med 2013; 25: 34. PMID:24472511, DOI:10.1186/2052-4374-25-34

21. Kuwahara K, Uehara A, Yamamoto M, Nakagawa T, Honda T, Yamamoto S, Okazaki H, Sasaki N, Ogasawara T, Hori A, Nishiura C, Miyamoto T, Kochi T, Eguchi M, Tomita K, Imai T, Nishihara A, Nagahama S, Murakami T, Shimizu M, Kabe I, Mizoue T, Kunugita N, Sone T, Dohi S, Japan Epidemiology Collaboration on Occupational Health Study Group: Current status of health among workers in Japan: results from the Japan Epidemiology Collaboration on Occupational Health Study. Ind Health 2016; 54: 505-514. PMID:27430963, DOI:10.2486/indhealth.2016-0082

22. Ministry of Health, Labour and Welfare. Active Guide: Japanese Official Physical Activity Guidelines for Health Promotion. Brochure in English. March 2013. Available at: http://www0.nih. go.jp/eiken/info/pdf/active2013-e.pdf. Accessed on July 29, 2017.

23. Studenski S, Perera S, Patel K, Rosano C, Faulkner K, Inzitari M, Brach J, Chandler J, Cawthon P, Connor EB, Nevitt M, Visser M, Kritchevsky S, Badinelli S, Harris T, Newman AB, Cauley J, Ferrucci L, Guralnik J: Gait speed and survival in older adults. JAMA 2011; 305: 50-58. PMID:21205966, DOI:10.1001/jama.2010.1923

24. Min C, Noh H, Kang YS, Sim HJ, Baik HW, Song WO, Yoon J, Park YH, Joung H: Skipping breakfast is associated with diet quality and metabolic syndrome risk factors of adults. Nutr Res Pract 2011; 5: 455-463. PMID:22125684, DOI:10.4162/nrp.2011.5.5.455

25. Ogura M, Nagashima J, Iida K, Kawamura M, Hashinishi M, Kurimoto M, Kondo J, Moriyama M, Nakagawa K, Nakagawa T: Analysis of lifestyle habits associated with metabolic syndrome. Ningen Dock 2010; 25: 803-810 (in Japanese).

26. Nanri A, Mizoue T, Takahashi Y, Matsushita Y, Noda M, Inoue M, Tsugane S, Japan Public Health Center-based Prospective Study Group: Association of weight change in different periods of adulthood with risk of type 2 diabetes in Japanese men and women: the Japan Public Health Center-Based Prospective Study. J Epidemiol Community Health 2011; 65: 1104-1110. PMID:20628079, DOI:10.1136/jech.2009.097964
27. Lind L, Elmståhl S, Ärnlöv J: Change in body weight from age 20 years is a powerful determinant of the metabolic syndrome. Metab Syndr Relat Disord 2017; 15: 112-117. PMID:28339342, DOI:10.1089/met.2016.0121

28. Ministry of Health, Labour and Welfare. Injury compensation for overwork of 2016. http://www.mhlw.go.jp/stf/houdou/0000168672.html Accessed on August 15, 2017.

29. Freedman DM, Sigurdson AJ, Rajaraman P, Doody MM, Linet MS, Ron E: The mortality risk of smoking and obesity combined. Am J Prev Med 2006; 31: 355-362. PMID:17046405, DOI:10.1016/j.amepre.2006.07.022

30. Ministry of Health, Labour and Welfare, Monthly Labour Survey 2014. http://www.mhlw.go.jp/toukei/list/30-1a.html. Accessed on July 29, 2017.

31. Gibson R, Eriksen R, Singh D, Vergnaud AC, Heard A, Chan Q, Elliott P, Frost G: A cross-sectional investigation into the occupational and socio-demographic characteristics of British police force employees reporting a dietary pattern associated with cardiometabolic risk: findings from the Airwave Health Monitoring Study. Eur J Nutr 2017; Epub ahead of print. PMID:29098424, DOI:10.1007/s00394-017-1562-4

32. Nomoto M, Hara A, Kikuchi K: Effects of long-time commuting and long-hour working on lifestyle and mental health among school teachers in Tokyo, Japan. J Hum Ergol (Tokyo) 2015; 44: 1-9. PMID:27281916

33. Artazcoz L, Cortès I, Escribà-Agüir V, Cascant L, Villegas R: Understanding the relationship of long working hours with health status and health-related behaviours. J Epidemiol Community Health 2009; 63: 521-527. PMID:19254912, DOI:10.1136/ jech.2008.082123

34. Kales SN, Straubel MG: Obstructive sleep apnea in North American commercial drivers. Ind Health 2014; 52: 13-24. PMID:24317450, DOI:10.2486/indhealth.2013-0206

35. Cotrim T, Carvalhais J, Neto C, Teles J, Noriega P, Rebelo F: Determinants of sleepiness at work among railway control workers. Appl Ergon 2017; 58: 293-300. PMID:27633225, DOI:10.1016/j. apergo.2016.07.006

36. Tsukahara T, Okano H, Eguchi H, Tsukahara Y, Tsuda Y, Urushihata K, Fujimoto K, Nomiyama T: The study of the relationship between RDI and BMI or sleepiness in workplace. Shinshu Soc Public Health 2011; 5: 105-109 (in Japanese).

37. Mansur AP, Rocha MA, Leyton V, Takada JY, Avakian SD, Santos AJ, Novo GC, Nascimento AL, Muñoz DR, Rohlfs WJ: Risk factors for cardiovascular disease, metabolic syndrome and sleepiness in truck drivers. Arq Bras Cardiol 2015; 105: 560-565. PMID:26761367

38. Suwazono Y, Okubo Y, Kobayashi E, Nogawa K: Effect of truck driving on health of Japanese middle aged male workers of a transport company - multiple regression analyses for blood pressure and $\mathrm{HbA}_{1 \mathrm{C}}$. J Occup Health 2000; 42: 239-244. DOI:10.1539/ joh.42.239

39. Birdsey J, Sieber WK, Chen GX, Hitchcock EM, Lincoln JE, Nakata A, Robinson CF, Sweeney MH: National Survey of US LongHaul Truck Driver Health and Injury: health behaviors. J Occup Environ Med 2015; 57: 210-216. PMID:25654523, DOI:10.1097/ JOM.0000000000000338 